\title{
Physiotherapists perceived role in managing anxiety in patients with relapsing-remitting multiple sclerosis: a mixed-methods study
}

Lauren Lucas ${ }^{1,2,3^{*}}$ (D) and Jack Parker ${ }^{1,3}$

\begin{abstract}
Background: Anxiety is common for people with Multiple Sclerosis (PwMS) and is higher in those with relapsingremitting MS (RRMS) and in community-based samples. Anxiety can impact self-efficacy, pain, fatigue, engagement in physical activity and treatment adherence, all of which influence the rehabilitation process. Little is known about how physiotherapists manage anxiety in PwMS and the challenges associated with anxiety throughout the rehabilitation process, in community and outpatient settings.

Methods: A mixed-methods design, combining a cross-sectional survey and semi-structured interviews with UKphysiotherapists, was used to answer the research question. To inform the qualitative study, a cross-sectional survey collected data from physiotherapists working in neurology to understand the impact and management of anxiety in people with MS (PwMS) during rehabilitation. Analysis used descriptive statistics and the findings formed the interview guide. Semi-structured interviews with specialist physiotherapists explored barriers and facilitators to managing anxiety in PWMS in community and outpatient settings, identified perceived physiotherapy training needs and offered suggestions to develop physiotherapy research and practice. Themes were derived inductively.

Results: The survey suggested how PwMS present with anxiety, its impact during rehabilitation, physiotherapy management practices, and physiotherapist skills and training needs. Five semi-structured interviews with specialist physiotherapists expanded on the survey findings and identified five main themes: Understanding the MS journey, modifying assessment and treatment, anxiety management toolbox, lagging behind Musculoskeletal Physiotherapy, and gaining knowledge and skills.

Conclusion: Physiotherapists encounter anxiety in PwMS in community and outpatient rehabilitation and perceive they have a role in managing it as it presents. Facilitators included communication, listening skills and opportunities to develop strong therapeutic relationships. Poor training and support, lack of clinical guidelines and limited research evidence were considered barriers. Clinically relevant learning opportunities, interprofessional working, and greater support through clinical supervision is recommended to better develop physiotherapy practice.
\end{abstract}

Keywords: Physiotherapy, Neurological rehabilitation, Community rehabilitation, Multiple sclerosis, Anxiety

\footnotetext{
* Correspondence: lauren.lucas1987@gmail.com

'School of Health and Related Research (ScHARR), University of Sheffield, Sheffiled, UK

${ }^{2}$ Present address: Salford Royal NHS Foundation Trust; Community Stroke and Neuro Rehab Team, Sandringham House, Salford M5 4DG, UK Full list of author information is available at the end of the article
}

C C The Author(s). 2022 Open Access This article is licensed under a Creative Commons Attribution 4.0 International License, which permits use, sharing, adaptation, distribution and reproduction in any medium or format, as long as you give appropriate credit to the original author(s) and the source, provide a link to the Creative Commons licence, and indicate if changes were made. The images or other third party material in this article are included in the article's Creative Commons licence, unless indicated otherwise in a credit line to the material. If material is not included in the article's Creative Commons licence and your intended use is not permitted by statutory regulation or exceeds the permitted use, you will need to obtain permission directly from the copyright holder. To view a copy of this licence, visit http://creativecommons.org/licenses/by/4.0/ The Creative Commons Public Domain Dedication waiver (http://creativecommons.org/publicdomain/zero/1.0/) applies to the data made available in this article, unless otherwise stated in a credit line to the data. 


\section{Background}

Multiple Sclerosis (MS) is a chronic, inflammatory condition affecting the central nervous system and is the most common neurological disorder diagnosed in young adults globally [1, 2]. Around $85 \%$ of People with MS (PwMS) will be diagnosed with Relapsing-Remitting MS (RRMS) at onset, characterised by unpredictable periods of stability (remission) and relapse of symptoms [3]. A recent study found that a relapsing-remitting disease course is a significant predictor for clinically significant anxiety [4]. As many as 66\% of people with RRMS report having anxiety [5] with greater prevalence in community-based samples [6]. However, despite this finding, anxiety is often overshadowed by depression, resulting in undertreatment and its presence being overlooked by many health professionals [7]. Anxiety is strongly associated with higher disability levels and significantly impacts pain and fatigue [8]. It also contributes towards poor treatment adherence, lower social support and social functioning, and poor health behaviours such as smoking and drinking to excess [8]. In PwMS, anxiety can explain low levels of physical activity, with significant interaction between anxiety and selfefficacy [9]. A recent study suggests that as much attention be paid to anxiety as depression, given that it plays a large role in PwMS's perceived health and well-being, subsequently impacting severity of symptoms and quality of life [7].

Physiotherapists play an essential part in MS management through provision of evidence-based rehabilitation focused on body functions, activities, and participation [3]. Health promotion, to manage risk factors for relapse and disease progression, also constitutes part of the physiotherapist's role [3]. However, the impact of anxiety throughout the rehabilitation process is not well known, nor are there clinical guidelines to support physiotherapists in this area. Few studies have investigated how physiotherapists manage anxiety in their patients, even fewer directly relate to neurological rehabilitation. In mental health settings, recognition of psychosomatic symptoms to differentiate between physical symptoms or those exacerbated by anxiety was considered a key skill by physiotherapists working in this area [10]. In vestibular rehabilitation, refined listening and communication skills were perceived to be important to understand the psychosocial complexities of patients, demonstrate empathy, and explain and normalise feelings, to build stronger therapeutic relationships [11]. Approaches used by physiotherapists to manage anxiety are varied, often selected based on clinical experience rather than research evidence $[11,12]$. Early research found physiotherapists use core skills of touch and movement; exercise being the most selected treatment, followed by relaxation and breathing retraining [12]. More recently, greater emphasis has been placed on utilising outcome measures to identify anxiety, with the foundation of treatment being talking and education [11]. The absence of physiotherapy specific clinical guidelines around anxiety management and psychosocial issues continues to be a significant barrier in clinical practice $[11,12]$.

In their work, Danielsson et al. [13] and Olund et al. [14] suggest homelikeness as a valuable theoretical framework for the physiotherapy management of anxiety. In this context, the concept of homelikeness relates to the impact of anxiety on the structure of one's existence, in which the body is a central component. The authors propose that patients experience a disintegration from their body and suggest physiotherapists can address this loss of homelikeness by providing a better understanding and connectedness to the body. In relation to MS where patients experience physical, cognitive and emotional changes contributing to a loss of identity, [15] this concept may offer a better understanding of the MS illness experience and inform how physiotherapists approach rehabilitation in this patient group. Patients with higher levels of anxiety have worse reports of MS symptomology, psychological well-being, quality of life and have poorer disease management [7]. Flensner and Rudolfsson [16] suggest living with MS means 'learning to fly with broken wings', encouraging health professionals to walk with patients on their journey to reconciliation and building a new living space in the body. This process relies on health professionals supporting PwMS to find their path towards health and adjust to living in a body affected by a chronic condition, therefore managing the physical, social and psychological aspects of MS.

The inter-relation between the social, psychological and impairment related aspects of MS can introduce barriers during the rehabilitation process [17]. However, guidance on appropriately managing these issues appears to be lacking. Despite the link between mental and physical health being broadly accepted, health professionals often report being underprepared to manage both of these aspects of a patient's health [18]. Clinical experience suggests that anxiety can be a barrier to PwMS achieving their intended physiotherapy goals, but also to physiotherapists in their ability to manage it effectively whilst waiting for psychotherapy services to become involved. This becomes more difficult in community and outpatient settings with fewer opportunities for collaborative working with psychologists and the wider multidisciplinary team. The aim of this study therefore, was to explore how physiotherapists manage anxiety in patients with RRMS in community and outpatient settings and suggest recommendations for future research and practice. The research question for this study was: 
1) What are the experiences of physiotherapists managing anxiety in patients with RRMS in community and outpatient settings and how can knowledge of these be used to better develop physiotherapy practice?

\section{Methods \\ Design}

A mixed-methods study, involving an online survey and semi-structured interviews, was undertaken with UK-based specialist physiotherapists between April and August 2018 as part of a Masters research project. Sequential data collection, with quantitative data collected and analysed to develop the interview schedule, connected data at the analysis stage. As the research problem was conceptualised inductively, through observation in clinical practice and shared experience with other clinicians, greater importance was placed on the qualitative arm of the study. Research ethics approval was granted by the University of Sheffield (March 2018, Reference number: 018256).

\section{Sample}

One hundred and ninety UK-based Chartered Physiotherapists registered with the Association of Chartered Physiotherapists in Neurology (ACPIN) were invited by email to complete an online questionnaire. ACPIN is a physiotherapy special interest group providing access to a national database of physiotherapists who volunteer to participate in research within registered areas of speciality. Following approval, the 190 members with a registered interest in MS were contacted by the ACPIN gatekeeper to complete a self-administered online survey. Physiotherapists working in community and outpatient neurology at Sheffield Teaching Hospital NHS Trust, Sheffield and Manchester MS Therapy Centres, and a small number of private practices were also invited to participate using gatekeepers in each location. It has been suggested that the UK National Health Service (NHS) physiotherapy provision is insufficient in meeting the needs of PwMS, [19] with the MS Society and MS Trust suggesting patients seek alternative input from MS Therapy Centres or the private sector. Therefore, it was deemed important to include both public and private sector physiotherapists in the sampling frame. As the number of physiotherapists working with PwMS is unknown, the most efficient way of obtaining data was through non-probability sampling. Although this method often pertains to selection bias, [20] it was unavoidable given the time and financial constraints on this student project. Eligibility criteria included having a registered interest in MS with ACPIN, and currently working or with recent experience of working with PwMS in community and outpatient settings. Physiotherapists working in inpatient neurorehabilitation were excluded. One reminder email was sent after 3 weeks.

\section{The survey}

As there are no standardised tools available to measure the phenomenon under investigation, a questionnaire was developed using Google Forms; free to use and complying with University information governance policy. Questions were derived by LL based on direct clinical experience, gathering data relating to the impact of anxiety in PwMS during rehabilitation, physiotherapists skills and techniques to manage anxiety, perceived areas for further physiotherapy training and demographic characteristics. The questions were reviewed by a second researcher (JP) prior to piloting. The questionnaire consisted of predominantly closed questions using rankedresponse, multiple choice, and Likert scales. This aimed to ease understanding for participants completing a selfadministered survey and enhance the value of data obtained. Open ended questions were minimised to lessen the burden on clinicians and reduce obtaining incomplete data. The questionnaire was piloted with a sample of 3 physiotherapists, representing the target population and having shared experience with the researcher prior to this study, to enhance validity and reliability. Minor amendments were made to improve question clarity. Distribution issues delayed the questionnaire being sent; therefore, the response window was extended by a month to gain sufficient data to inform the qualitative arm of the study. The questionnaire was available from 21st May 2018 to the 2nd July 2018, aligning with the timeframe and deadline allocated to this masters project.

\section{Survey data analysis}

The survey responses were collated in Google Forms and transferred into an Excel document for analysis. Ordinal data was coded using a 'maximum response score' based on the total number of responses and analysed in Excel. As the study used a non-probability sample, inferential statistics were not used as the purpose of the quantitative phase was not to generalise to the wider population [21]. Results were reported using descriptive statistics, with percentages chosen to enhance understanding of distributions within the data [22]. Missing data were excluded from analyses, with only one question missing a response.

\section{The interview guide}

Explanatory mixed-methods designs use qualitative methods to explore quantitative findings in depth, requiring the researcher to identify surprising, unclear or unexpected results that require further explanation [23]. Following quantitative analysis, semi-structured questions were developed to determine how anxiety in PwMS 
impacts the rehabilitation process, understand the physiotherapists role in managing anxiety, explore training needs and identify areas for further exploration [24]. The questions, summarised in Table 1, were developed based on the quantitative findings, were reviewed by a senior academic colleague (JP) and amended to avoid leading or loaded questions [25]. The guide was also piloted on a physiotherapy colleague impartial to the project, to ensure adequate information was elicited, avoid socially desirable responses, and establish an effective interviewing technique $[25,26]$.

\section{The interviews}

Purposeful sampling of Physiotherapists involved in the quantitative study were invited via gatekeepers to participate in the interviews. Eligibility included physiotherapists working in neurology with current or previous experience in community or outpatient neurorehabilitation. Physiotherapists working in inpatient neurorehabilitation were excluded. Face-to-face and telephone interviews were offered to enhance participation in the study. Informed consent was gained in written format prior to the interview. Five interviews were conducted, lasting between 22 and $49 \mathrm{~min}$ in total. Data saturation was achieved when no new ideas were generated in the interviews, therefore further data collection was considered counter-productive (Saunders et al., 2018) [27]. Collection of demographic information provided additional context to the data. Interviews were transcribed verbatim and anonymised by LL as part of this master's project, following which the original recording was deleted from the recording device to minimise any breaches of confidentiality. Although respondent

Table 1 Summarised interview guide informed by findings from the quantitative survey and literature search

\section{Questions informed by the literature search:}

- Questions related to the impact of anxiety on the rehabilitation process including perceived barriers

- Attitudes towards physiotherapists having a role in managing anxiety and psychological wellbeing in PwMS during the rehabilitation process - How the profession can move to consider psychological aspects of health and wellbeing in PwMS and other neurological conditions/in neurological rehabilitation settings

\section{Questions informed by the quantitative survey:}

- Exploring prioritisation of anxiety, depression and stress.

- Having high expectations of others vs. what patients expect from physiotherapy in relation to physical and psychological wellbeing - Issues associated with trouble concentrating, worry and avoidance during the rehabilitation process and how these are managed clinically Exploration of physiotherapists feeling comfortable asking about mental health but less comfortable acting on disclosures

- Effective treatment approaches to managing anxiety in PwMS and useful interventions/training/skills for improving in this area in the future

- Exploration of psychological content of training and moving forward in this area validation enhances the credibility of qualitative data, [28] it was not completed in this case as the additional burden on practitioner time was deemed to be too great.

\section{Data analysis}

Data were analysed using Braun and Clarkes thematic analysis [29]. Complete coding, using NVivo 12 software, identified all incidences deemed interesting or relevant to the research question [25]. With limited existing research on the topic, thematic analysis at a latent level examined the underlying assumptions, ideas and ideologies shaping the semantic substance of the data [29]. This involved producing researcher-derived codes to identify implicit, rather than explicit meaning [25]. An inductive approach to analysis ensured themes were grounded in participants responses [30]. Themes and supporting quotes are detailed in Table 2. Qualitative data were reported in line with the Enhancing Transparency in Reporting the Synthesis of Qualitative Research (ENTREQ) statement [31]. It is recognised that credibility would be enhanced by using more than one researcher during the data analysis process, and by asking the participants for their feedback [32]. However, due to time and resource constraints of this masters project and perceived burden on practitioner time, it was not feasible in its entirety for this study. To ensure interpretation of the data was objective, therefore as valid as possible, the anonymised transcript of the first interview was reviewed by a student colleague and the codes were further developed before continuing the analysis process.

\section{Results}

\section{Quantitative phase}

Eleven respondents, characterised in Table 3, completed the survey with one question missing a response. All participants were female and clinical experience ranged between 1 and 38 years. Of the respondents, $n=9$ (82\%) worked in community, outpatient, or private practice neurology settings and $n=2(18 \%)$ worked in other areas but had experience in neurology. Five respondents (45\%) had postgraduate training in psychological interventions. Of those, $n=3(60 \%)$ had training in motivational interviewing (MI), $n=1$ (20\%) in cognitive behavioural therapy (CBT), and $n=1(20 \%)$ had informal training.

\section{How people with RRMS present}

Respondents reported that stress (63\%), depression (59\%) and sadness (57\%) were most frequently encountered in PwMS however, anxiety and depression were prioritised as most important to manage during physiotherapy interventions (Fig. 1). Trouble concentrating (56\%) and worry (53\%) were common emotional symptoms observed, followed by avoidance $(41 \%)$. To understand the impact of anxiety in relation to rehabilitation, 
Table 2 Themes, subthemes and examples of quotes from qualitative interviews

\section{CURRENT PRACTICE}

\section{Theme 1: Understanding the MS Journey}

\section{Subtheme: Physiotherapist Role}

"It's being able to know when it's not actually for you and you need to hand it over" (PT1)

"I guess for neuro there's that really good understanding of the acceptance journey that people go on. Because that's when we see anxiety come out, that's when we see depression come out, that's when we see anger and frustration and those, and probably that difference between what's "normal" anxiety and depression and moving on that journey of grief and acceptance and what's dysfunctional and potentially dangerous" (PT5)

\section{Subtheme: Patient's expectations}

"I think MS patients' expectation of physio in general is quite high because they see physio as the thing that's going to get them better because there isn't a wonder drug. With MS it isn't like that, they, they hang everything on their physio." (PT2)

"We have some people who come expecting somebody to do something to them ... and convincing people to continue exercises, or other interventions anyway, when they're not here can be quite difficult" (PT3)

\section{Theme 2: Modifying assessment and treatment}

\section{Subtheme: Impact of anxiety}

"I think the anxiety, if people have that when they come in for whatever reason, that can really sort of inhibit how much they take on." (PT3)

"How good are we at you know, having our own strategies to work with that population, remain positive and not get to that point of burn out or, stress or, beating yourself up because you think you haven't delivered a good session" (PT5)

\section{Subtheme: Management strategies}

"I'm not sure that the GP would always be the best person to help deal with [anxiety], but they might have access to local services to help that patient ... the MS nurses are really good sources of information and support for patients." (PT3)

"I think that signposting to the more psychological therapies, I think we have to be really knowledgeable about those things." (PT5)

\section{Theme 3: Anxiety management toolbox}

\section{Subtheme: Skills and attributes}

"I think you can alleviate somebody's worry just by talking to them." (PT2)

"I think the ability to empathise and to listen and to give a degree of understanding and gain a rapport, its all, it's all involved in being able to effectively communicate both verbally and non-verbally I guess" (PT4)

Subtheme: Barriers and facilitators

"its lack of confidence and feeling like they haven't got the tools in their tool kit to be able to give the appropriate advice to people." (PT2)

"I think if you were going into it and you were newly qualified, I think you wouldn't want to be delving into that area because you probably don't have that experience to go off" (PT4)

"Perhaps there's something about us looking in, I talked about supervision. If you look at psychology, social work or OT*, they're really good at addressing their own wellbeing within supervision." (PT5)

\section{MOVING FORWARDS}

\section{Theme 4: Lagging behind MSK*}

"They're getting better at that in MSK than we possibly are in neuro... Pete O'Sullivan people like that are doing courses where you're listening to the patient's story and what that is actually telling you about how that's impacting them, and I think that's really important" (PT2)

"If you look within chronic pain there is evidence that psycho-education changes people's physical symptoms or experience of pain. If we can do that in chronic pain, we can do that in every condition." (PT5)

\section{Theme 5: Gaining knowledge and skills}

\section{Subtheme: Interprofessional working}

"I'm sure that the MS nurses will do absolutely loads of psychological support, because you know in their role, so actually there's probably a lot that we could learn and a lot that we could share between us." (PT1)

"Learning from psychology, I've learned heaps from working with psychologists" (PT5)

\section{Subtheme: Physiotherapy training}

"At an undergrad level it needs much more emphasis, about we need to look at the whole person and looking at the evidence now that supports how the psychological impact of things affects physical symptoms, we're no longer just treating physical symptoms were treating the whole patient." (PT2)

"more of a guidance package than a training package sort of you know ... coming sort of centrally as part of CSP*, guidance or case studies for example on iCSP" (PT3)

${ }^{*}$ CSP Chartered Society of Physiotherapy *MSK Musculoskeletal *OT Occupational Therapy

physiotherapists were asked to consider negative patterns associated with anxiety and the extent to which they arose in PwMS clinically. High expectations of others $(80 \%)$, dwelling on the past $(70 \%)$, over generalising (70\%) and labelling (70\%) were most frequently observed.

\section{Managing anxiety in clinical practice}

Respondents identified anxiety in PwMS through informal conversations with other members of the team
(91\%), however Multidisciplinary Team meetings were not selected by any participants. Self-reporting from patients constituted $91 \%$ of the responses and most participants $(82 \%)$ felt clinical experience was a significant factor for identifying anxiety. All participants felt confident asking about mental health problems, however responses were widely spread in relation to acting on, or dealing with a disclosure (Fig. 2). Table 4 details treatment approaches for anxiety used by the respondents. Goal setting (91\%) was most common, followed by 
Table 3 Demographic characteristics of survey respondents

\begin{tabular}{|c|c|c|}
\hline & & $\begin{array}{l}\text { Frequency } \\
(n=11)\end{array}$ \\
\hline \multirow[t]{2}{*}{ Gender } & Female & 11 \\
\hline & Male & 0 \\
\hline \multirow[t]{2}{*}{ Type of Work } & Full time & 4 \\
\hline & Part time & 7 \\
\hline \multirow[t]{4}{*}{ Area of work } & Outpatient clinic & 5 \\
\hline & Community & 1 \\
\hline & Private practice & 3 \\
\hline & Other (with Neuro experience) & 2 \\
\hline \multirow[t]{5}{*}{ Region of work } & South West & 3 \\
\hline & East of England & 1 \\
\hline & London & 2 \\
\hline & Yorkshire and the Humber & 2 \\
\hline & Not reported & 3 \\
\hline \multirow[t]{4}{*}{ Years of experience } & $1-10$ years & 1 \\
\hline & $11-20$ years & 5 \\
\hline & $21-30$ years & 2 \\
\hline & $30+$ years & 3 \\
\hline Range of experience (years) & $1-38$ & \\
\hline Mean years of experience & 22.9 & \\
\hline Median years of experience & 20 & \\
\hline Post graduate training in & Yes & 5 \\
\hline psychology & No & 6 \\
\hline \multirow[t]{3}{*}{ Type of training } & Cognitive Behavioural Therapy & 1 \\
\hline & Motivational Interviewing & 3 \\
\hline & Informal training & 1 \\
\hline
\end{tabular}

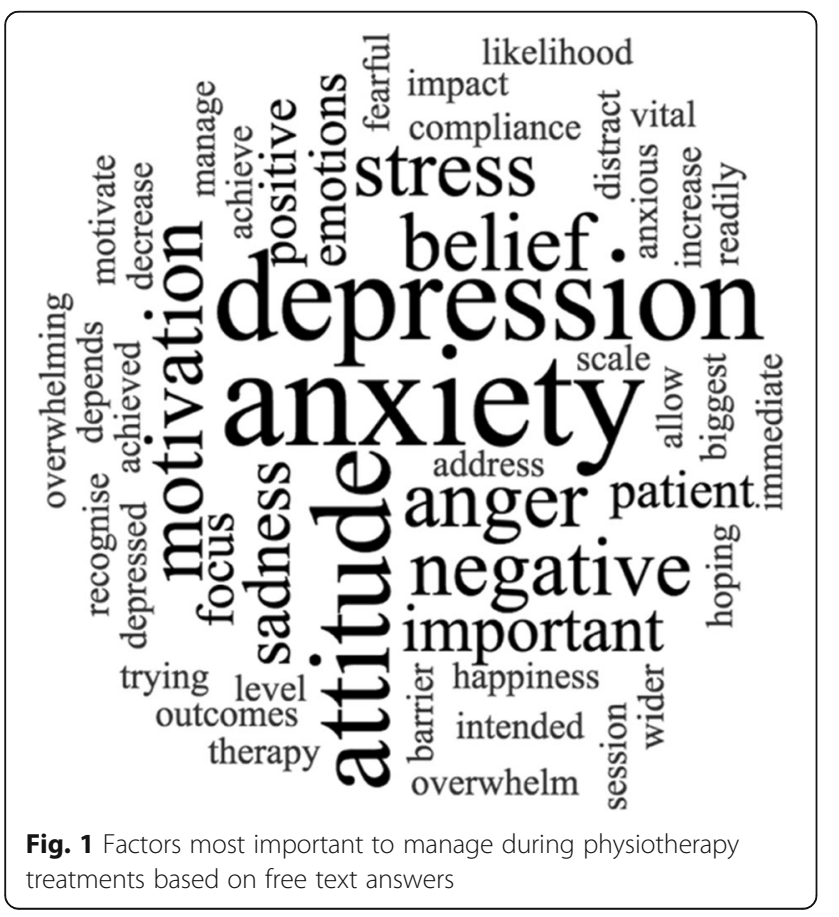

relaxation (82\%) and reflective listening (73\%). Despite only 3 participants receiving training in motivational interviewing, it was a treatment approach selected by 7 participants (64\%).

Skills and training required to manage anxiety in patients Effective communication (89\%) and listening skills (88\%) were deemed most important to managing anxiety. However clinical experience (61\%) and working towards goals (59\%) were less important, despite goal setting being the most frequently used treatment technique for anxiety. Involving the Multidisciplinary Team (55\%) and offering advice (39\%) was least important. Figure 3 details participants responses to identifying interventions useful for managing anxiety and indicating those where additional training would be useful. Interestingly, motivational interviewing scored similarly in its value as an intervention in clinical practice $(57 \%)$ and additional training (58\%). Similar incidence was found for mindfulness, scoring 53 and 57\% respectively. Most participants (82\%) agreed psychology was an important part of physiotherapy training. However, responses were skewed regarding effectiveness of undergraduate training in 


\section{A chart to show the confidence of physiotherapists asking about and acting on mental health issues.}

\section{Q: How comfortable are you asking patients about their mental health?}

Q: How comfortable are you in acting on/dealing with disclosure?

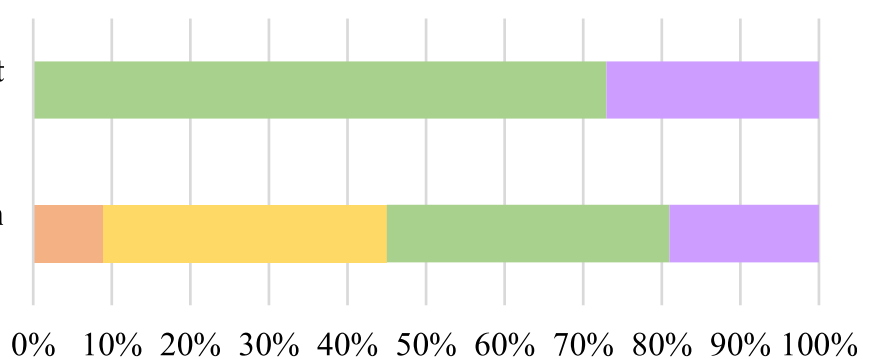

$\square 1$ (not comfortable at all) $\square 2 \square 3 \square 4 \square 5$ (very comfortable)

Fig. 2 Percentage of survey responses for questions around confidence asking about mental health and acting on disclosures $(n=11)$

providing skills to successfully navigate patient psychological wellbeing.

\section{Qualitative phase}

Five physiotherapists, characterised in Table 5, participated in semi-structured interviews. All participants worked in neurology with a greater proportion having experience in MS therapy centres $(n=3)$. Three participants worked in community and outpatient settings whilst two worked in clinic settings. Three participants received informal psychological training. Figure 4 displays a visual representation of the overarching themes, themes and subthemes. A single direction arrow establishes hierarchical relationships; bi-directional arrows indicate close lateral relationships; a dashed line signals a tentative relationship.

Table 4 Table summarising treatment techniques used to manage anxiety

\begin{tabular}{ll}
\hline Treatment technique & $\begin{array}{l}\text { Frequency }(\boldsymbol{n}=\mathbf{1 1}) \\
\%(\mathbf{n})\end{array}$ \\
\hline Goal setting & $91 \%(10)$ \\
Relaxation & $82 \%(9)$ \\
Reflective listening & $73 \%(8)$ \\
Motivational Interviewing & $64 \%(7)$ \\
Workbooks / paper resources & $64 \%(7)$ \\
Coping Strategies & $55 \%(6)$ \\
Mindfulness & $55 \%(6)$ \\
Positive reinforcement & $45 \%(5)$ \\
Imagery / visualisation & $36 \%(4)$ \\
Self-talk & $27 \%(3)$ \\
Cognitive Behavioural Therapy (CBT) & $18 \%(2)$ \\
Acceptance and Commitment Therapy (ACT) & $0 \%(0)$ \\
\hline
\end{tabular}

Theme1: understanding the MS journey

A common idea was understanding the MS journey significantly differs to other neurological conditions. Within this theme participants discussed their role when treating PwMS, patient expectations and the challenges they face.

\section{Subtheme: physiotherapist role}

In addition to facilitating movement and function, physiotherapists are required to support acceptance and adjustment following a life-altering health event or diagnosis. This requires understanding the MS illness experience, the impact on social, family and life roles and manage anxieties related to these factors. Despite being well placed to take an active role in managing anxiety in clinical interactions, they recognised the importance of working within their scope of practice and seeking support elsewhere in more challenging situations.

\section{Subtheme: Patient's expectations}

A significant challenge was the importance placed on physiotherapy, from patients and other professionals, to manage symptoms in the absence of any curative treatment. Misconceptions around physiotherapy necessitating hands-on treatment challenged productive selfmanagement discussions. As the measure of success is inherently different in progressive neurological conditions, physiotherapists often felt like they were not helping their patients therefore not meeting patient expectations.

\section{Theme 2: modifying assessment and treatment}

Participants acknowledged the many layers of anxiety that PwMS can face and recognised it exists within physiotherapy treatment sessions. In identifying the impact of these anxieties, participants reflected on how 


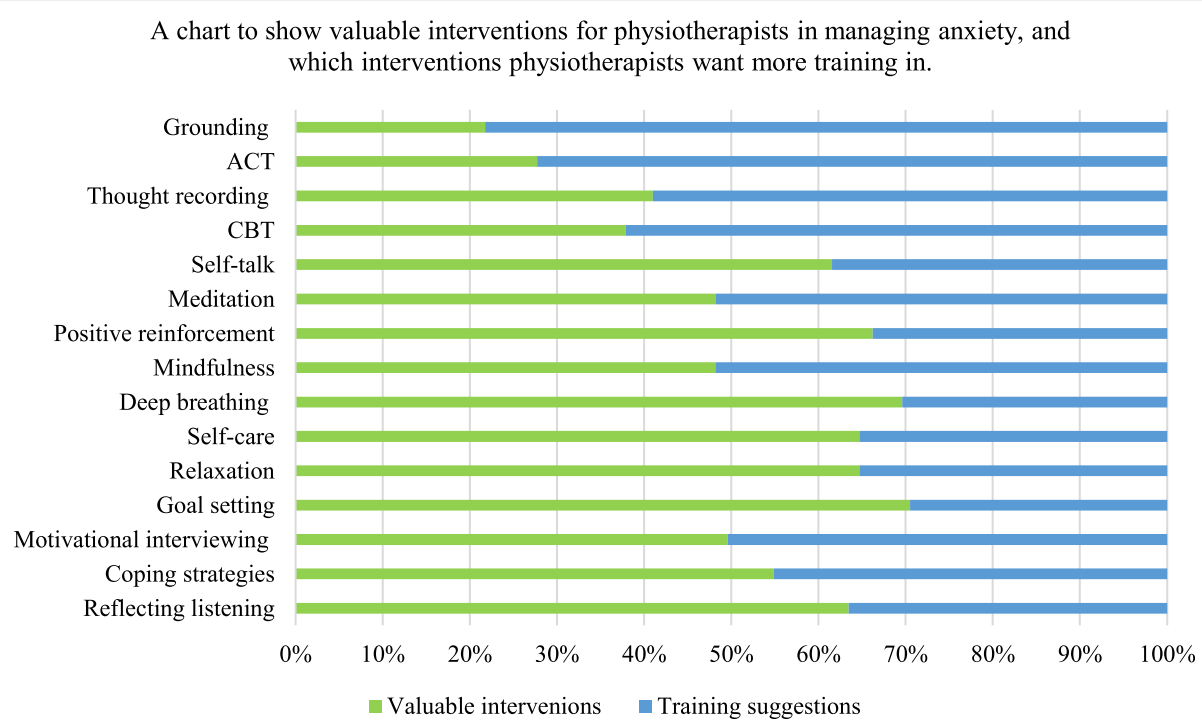

Fig. 3 A chart summarising the priority in which interventions are considered valuable to physiotherapists to manage anxiety, compared to which interventions are prioritised for additional training

they manage it as it presents, reflected in the following subthemes.

\section{Subtheme: impact of anxiety}

All participants reflected anxiety blocked treatment progression, particularly through greater time discussing anxiety related issues and the implications of this on physical progression. Participants felt physiotherapy itself contributed towards anxiety, referencing challenges to physical ability, indicating the importance of exploring the source and reflexively modifying treatment. Anxiety was detrimental to self-efficacy, affecting concentration and retention of information, therefore impeding self-management. An interesting insight was the impact of anxiety on physiotherapists, with clinicians feeling less competent in their clinical skills and noting feelings of inefficacy.

\section{Subtheme: management strategies}

All participants used treatment planning as an anxiety management strategy, ranging from task specific training

Table 5 Demographic characteristics of interview participants

\begin{tabular}{|c|c|c|}
\hline & & $\begin{array}{l}\text { Frequency } \\
(n=5)\end{array}$ \\
\hline \multirow[t]{2}{*}{ Gender } & Female & 5 \\
\hline & Male & 0 \\
\hline \multirow[t]{2}{*}{ Work setting } & National Health Service & 1 \\
\hline & Private practice & 4 \\
\hline \multirow[t]{2}{*}{ Experience working in MS therapy centre (current/past) } & Yes & 3 \\
\hline & No & 2 \\
\hline \multirow[t]{2}{*}{ Hours of Work } & Full time & 4 \\
\hline & Part time & 1 \\
\hline \multirow[t]{2}{*}{ Area of work } & Outpatient clinic only & 2 \\
\hline & Community \& Outpatient clinic & 3 \\
\hline \multirow[t]{3}{*}{ Frequency seeing PwMS } & Daily & 2 \\
\hline & Weekly & 2 \\
\hline & Fortnightly & 1 \\
\hline \multirow[t]{2}{*}{ Post graduate training in psychology } & Yes & 3 \\
\hline & No & 2 \\
\hline Type of training & Informal (in-service training) & 3 \\
\hline
\end{tabular}




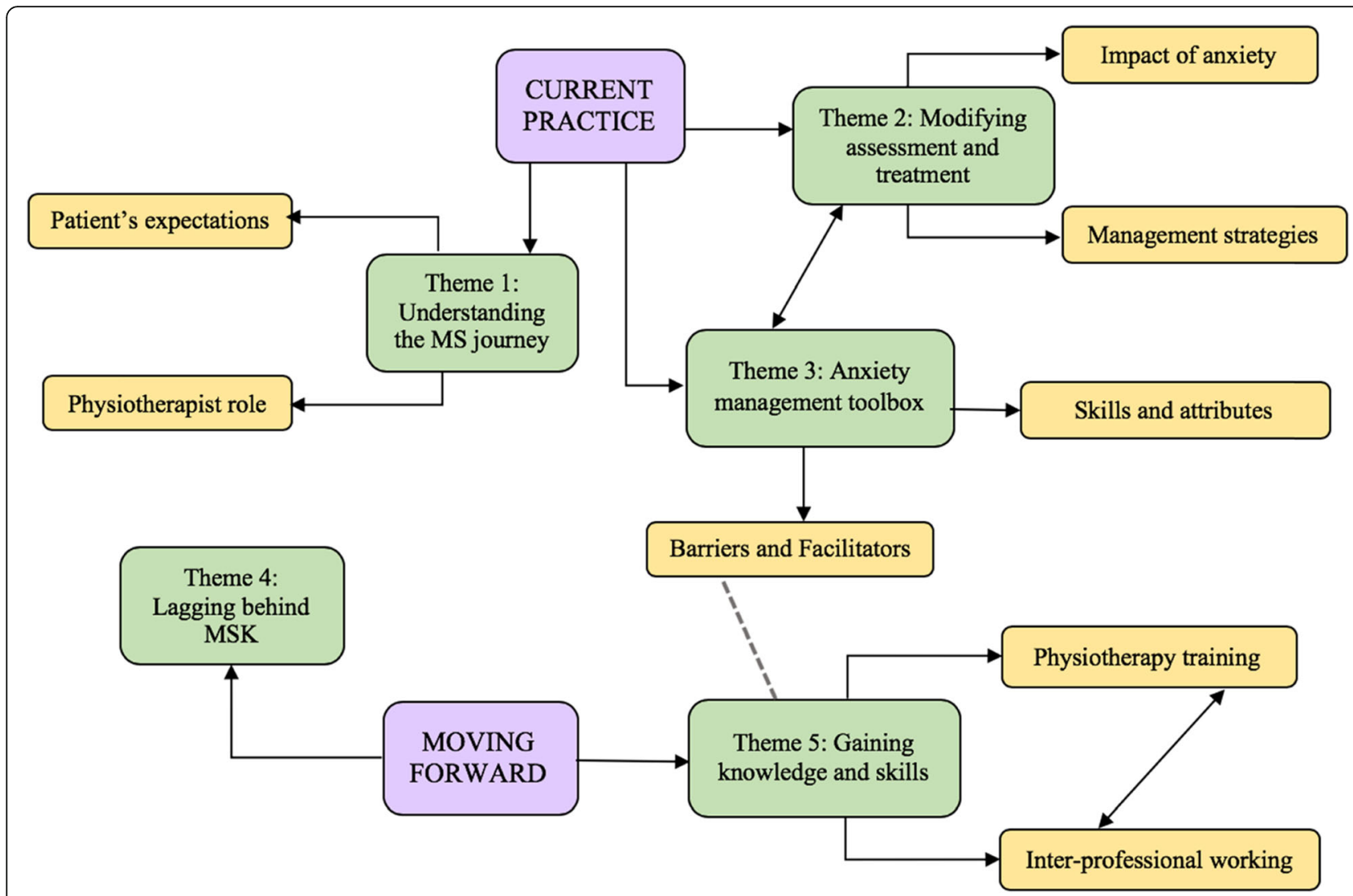

Fig. 4 Visual map of participant overarching themes, themes and subthemes

and goal setting, to changing the layout of the room. Education strategies varied between education relating to the physiotherapy process and psychoeducation to normalise anxiety symptoms. There were mixed views around using psychological interventions as part of physiotherapy treatment. Signposting and onward referrals were emphasised, with MS nurses being a more valuable resource than General Practitioner's. All participants adopted anxiety management strategies within their clinical practice, however expressed difficulty meeting the psychological needs of their patients.

\section{Theme 3: anxiety management toolbox}

Themes two and three are closely related as the process of managing anxiety does not solely rely on interventions and clinical approaches, but the skills required to employ them. The subthemes 'Skills and attributes' and 'barriers and facilitators' build upon what is required for physiotherapists to create an anxiety management toolbox.

\section{Subtheme: skills and attributes}

Interpersonal skills such as communication skills, active listening, and empathy to form stronger therapeutic relationships, underpinned the anxiety management toolbox.
Strong therapeutic relationships allow patients to open up about their worries allowing physiotherapists to alleviate concern, signpost accordingly and set specific rehabilitation goals. Clinical reasoning was important to evaluate the success of interventions, providing opportunity to question why progress may not as expected and address underlying issues, such as anxiety, posing as barriers.

\section{Subtheme: barriers and facilitators}

All participants felt strongly that undergraduate training did little to prepare new graduates for the challenges they are likely to face managing psychological wellbeing. Barriers included a lack of confidence and skills, inadequate undergraduate and postgraduate training opportunities, and clinical supervision. Facilitators included clinical setting and team support, having access to psychology input, and opportunity to build a therapeutic relationship.

\section{Theme 4: lagging behind MSK}

Participants felt neurological physiotherapy may be behind, in both research and practice, when looking at the link between physical and mental health. Reference was made to evidence supporting the psychosocial 
management of chronic pain within physiotherapy and how these principles could be applied to the neuro setting. Using patient narrative over gold standard research methods to understand the patient story was also deemed important in the context of neuro-research.

\section{Theme 5: gaining knowledge and skills}

Suggestions to gain knowledge and skills to effectively manage anxiety in PwMS were detailed in the following subthemes.

\section{Subtheme: Interprofessional working}

Interprofessional working was strongly woven through all of the interviews. This included working with psychology, MS nurses and occupational therapists, and the recommendation of a network for therapists interested in MS. Despite recognising that interprofessional working was important, it was noted that this opportunity may not be available to all therapists.

\section{Subtheme: physiotherapy training}

Several suggestions to support physiotherapy training at undergraduate and postgraduate level were made. These included training in the use of psychologically informed physiotherapy and opportunities to enhance communication and listening, joint training with psychology and MS nurses, and utilising interactive, online training platforms through the Chartered Society of Physiotherapy.

\section{Discussion}

This study explores physiotherapists' perspectives on the impact and management of anxiety in PwMS. Participants felt it was part of their role to manage psychological and emotional wellbeing throughout the rehabilitation process and described the impact of anxiety on physiotherapy interventions. In the absence of current evidence or treatment guidelines, physiotherapists feel underprepared and often lack the confidence to do this effectively in clinical settings.

Anxiety was found to affect self-efficacy, participation, rehabilitation progression and treatment adherence, with many factors influencing the presence of anxiety in PwMS; factors directly relating to the disease, psychosocial issues, or the rehabilitation process itself. With the introduction of homelikeness theory to explain the presence of anxiety in the body, $[13,14]$ qualitative interviews highlighted both physical and social influences contributing towards feeling unhomelike. In the context of chronic illness, Svenaeus [33] suggests illness brings about feelings of unhomelikeness in the social world, reflected in the findings of this study. Similarly, Jingrot and Rosberg [34] discuss fatigues impact on homelikeness, fatigue being a common experience for PwMS and directly impacting upon anxiety. Despite this term not arising during the study, physiotherapists believed it was part of their role to alleviate the presence of anxiety, therefore mitigating unhomelikeness, using skills they felt were within their scope of practice.

Verbal and non-verbal communication, empathy and listening, were identified by Physiotherapists as key to managing anxiety in PwMS through developing strong therapeutic relationships. Similarly to vestibular rehabilitation, [11] participants emphasised development of listening and communication skills to build trusting relationships, allowing patients to open up about their problems. Participants in this study used these skills to manage anxiety in their patients and all physiotherapists thought this was within their scope of practice. However, despite extensive clinical experience in MS, views towards onward referrals to psychology varied dependent on confidence in their own skills to manage this aspect of MS. A recent study identified the intimate nature of the patient/physiotherapist relationship; patients disclosing personal information related to their wellbeing outside of the therapy setting, is one that is important for engagement in the therapeutic relationship [35]. However, there were several limitations to this, including its application to patients with neurological conditions due to therapeutic relationships extending to family members. Interestingly in this study, managing the wider impact of anxiety within family contexts was not discussed. Therefore, the wider extent to which the therapeutic relationship is utilised in community and outpatient neurological rehabilitation is unknown and may benefit from future research.

Despite feeling comfortable asking about mental health, findings indicated that physiotherapists were less comfortable acting on what might be disclosed, largely due to a perceived lack of skills to navigate difficult conversations. This is reflected in musculoskeletal physiotherapy where physiotherapists report inadequate skills, time, support and education to effectively assess and manage the complex psychosocial factors associated with chronic pain [36, 37]. Being long-term conditions, the physiotherapy management of chronic pain and MS is not dissimilar, with guidelines promoting selfmanagement [38-40]. However, the former places greater emphasis on concurrently managing both mental and physical wellbeing, with a move towards physiotherapists providing psychologically informed treatments such as cognitive behavioural therapy (CBT) and acceptance and commitment therapy (ACT). This has been found acceptable to patients [41, 42] and physiotherapists delivering these treatments, [43, 44] bringing into question why this expansion of the physiotherapist' role has not been considered in neurological rehabilitation. Few participants in this study used psychologically informed interventions in their practice. Although 
quantitative findings indicated that training in $\mathrm{ACT}$ and CBT may be beneficial, qualitative findings suggested that physiotherapists need only to expand their knowledge in these areas to support patient decision making. Due to the small sample size, further research would be needed to gain a broader understanding of how beneficial psychologically informed physiotherapy would be in community and outpatient neurorehabilitation.

In addition to a lack of skills, a significant barrier to physiotherapists feeling competent was inadequate training, at both undergraduate and post-graduate level. This reflects findings from other clinical settings where physiotherapists felt their training did not equip them with skills to meet the psychological needs of their patients $[18,45]$. Qualitative interviews suggested several recommendations for improvements in this area, for example the use of narrative to develop case studies and patient stories such as those used in chronic pain research. This study highlighted physiotherapists understand the impact of uncertainty and loss of identity associated with chronic disease, however, lack the skills to confidently manage the illness experience during rehabilitation. Narrative has been used to understand the lived experience of pain-related fear to better inform its physiotherapy management, reconceptualising assessment and treatment approaches as a result [46, 47]. A similar approach may be beneficial within neurological physiotherapy to better understand the multifaceted biopsychosocial aspects of MS that directly impact rehabilitation.

Interprofessional working and training was another recommendation to move forward in this area. However, opportunities for interprofessional working appear to be limited in community and outpatient settings, a finding reflected in the vestibular rehabilitation setting [11]. In psychiatry and pharmacology, the use of virtual learning environments has been shown to be effective at facilitating interprofessional learning at a post-graduate level $[48,49]$. This study indicated that physiotherapists may be open to online professional development and training facilitated through the Chartered Society of Physiotherapy (CSP) website and iCPS learning platform. Therefore, this approach may support interprofessional learning with psychologists and MS specialist nurses, using clinically relevant scenarios, case studies and patient stories. In addition to post-graduate training, ongoing supervision and reflective practice consolidates skills to manage psychological wellbeing effectively. Poor support and ineffective supervision can contribute towards burnout in physiotherapists, a concept directly affected by feelings of inefficacy [50]. The themes 'impact of anxiety' and 'patient expectations' introduced the idea of inefficacy, where physiotherapists reported the challenges of working with MS and self-criticism of their clinical skills. Interprofessional supervision may support greater skill acquisition and offer alternative perspectives to solving clinical problems.

This study has three main limitations. Firstly, despite efforts to avoid ambiguous questions in the design of the survey, the analysis stage highlighted the wording of questions may not have been clear, therefore affecting the validity of the results $[51,52]$. Due to resource limitations, collaboration to develop the survey was not possible. In addition to human error the questions may have lacked objectivity that could have been negated with input from a research team. This may also have been avoided using an exploratory sequential design to develop a context specific instrument, thus improving construct validity [23]. Poor survey response significantly limits the generalisability of the findings. Several reasons have been suggested to explain poor response rate in survey-based studies however, topic saliency and complexity of the survey may have contributed towards a poor response rate in this study. Lastly, findings from both phases may be biased towards gender, years of clinical experience and setting as all participants were female averaging 22 years clinical experience. A greater proportion also had experience working in MS Therapy Centres thus developing specialist skills. Therefore, the study findings cannot accurately reflect the experience of male physiotherapists or lower grade rotational physiotherapists with less clinical experience in neurology. Despite generating new knowledge on this topic, the results should be interpreted with caution due to the small sample size and limited resources available as part of this Master's project.

\section{Conclusion}

This study has implications for clinical practice, education and research. It demonstrates that physiotherapists perceive their role to include managing anxiety in PwMS, with anxiety impacting self-efficacy, participation, and engagement with self-management strategies in community and outpatient rehabilitation. However, a lack of confidence, skills, opportunity to obtain skills, clinical guidelines and clinical support remain ongoing barriers to developing in this area. This study highlights the need for ongoing training and development, at both undergraduate and postgraduate levels, to equip physiotherapists with the skills to support PwMS to 'learn to fly with broken wings'. Collaborative learning with the wider multidisciplinary team and MS specialists, can support the development of physiotherapists skills at all stages of their career.

There is limited research investigating how physiotherapists manage psychological wellbeing in patients with long-term neurological conditions. Moreover, little is known about the skills required to manage the wider impact of neurological conditions, for example family and 
carer wellbeing. Further research is required, using methodologies that accurately reflect the patient journey, to inform better understanding of the MS illness experience directly related to rehabilitation. This may lead to the development of psychologically informed interventions relevant to neurological physiotherapy and inform appropriate guidelines to support physiotherapists to manage anxiety across different clinical settings.

\section{Abbreviations}

ACPIN: Association of Chartered Physiotherapists in Neurology; ACT: Acceptance and Commitment Therapy; CBT: Cognitive behavioural therapy; CPD: Continuing professional development; CSP: Chartered Society of Physiotherapy; ENTREQ: Enhancing transparency in reporting the synthesis of qualitative research; MDT: Multidisciplinary Team; MI: Motivational interviewing; MSK: Musculoskeletal; OT: Occupational Therapy; PwMS: People with MS; RRMS: Relapsing Remitting Multiple Sclerosis

\section{Acknowledgements}

Not applicable.

\section{Authors' contributions}

LL was responsible for conceptualisation of the idea and methodology with supervision from JP as part of an MSc research project. LL completed investigations and formal analysis and the development of all study resources. The original draft was written by LL with review and editing by JP. All authors read and approved the final manuscript.

\section{Funding}

This research did not receive any specific grant from funding agencies in the public, commercial, or not-for-profit sectors.

\section{Availability of data and materials}

The datasets generated and/or analysed during the current study are not publicly available due to being stored on a private university network but are available from the corresponding author on reasonable request.

\section{Declarations}

\section{Ethics approval and consent to participate}

The University of Sheffield School of Health and Related Research (ScHARR) Research Ethics Committee approved this study. All participants gave written informed consent before data collection began.

\section{Consent for publication}

Not applicable.

\section{Competing interests}

The authors declare that they have no competing interests.

\section{Author details}

${ }^{1}$ School of Health and Related Research (ScHARR), University of Sheffield, Sheffiled, UK. ${ }^{2}$ Present address: Salford Royal NHS Foundation Trust; Community Stroke and Neuro Rehab Team, Sandringham House, Salford M5 4DG, UK. ${ }^{3}$ Present address: School of Human Sciences, University of Derby, Derby, UK

Received: 13 May 2021 Accepted: 3 November 2021

Published online: 11 January 2022

\section{References}

1. Wingerchuk DM, Lucchinetti CF, Noseworthy JH. Multiple sclerosis: current pathophysiological concepts. Lab Invest. 2001;81(3):263-81. https://doi.org/1 0.1038/labinvest.3780235.

2. Lassmann H, Bruck W, Lucchinetti C. Heterogeneity of multiple sclerosis pathogenesis: implications for diagnosis and therapy. Trends Mol Med. 2001;7(3):115-21. https://doi.org/10.1016/s1471-4914(00)01909-2.

3. National Institute for Health and Care Excellence. Multiple sclerosis in adults: management [Internet]. [London]: NICE; 08 October 2014 [updated 2019
Nov; cited 26 Jun 2018]. (Clinical guideline [CG186]). Available from: https:// www.nice.org.uk/guidance/cg186

4. Podda J, Ponzio M, Messmer Uccelli M, Pedullà L, Bozzoli F, Molinari F, et al. Predictors of clinically significant anxiety in people with multiple sclerosis: a one-year follow-up study. Mult Scler Relat Disord. 2020;45:102417. https:// doi.org/10.1016/.msard.2020.102417.

5. Rupprecht S, Kluckow S, Yahiaoui-Doktor M, Aktas O, Chan A, Dressel A, et al. Prevalence of sleep disturbances, fatigue, anxiety and depression in Multiple Sclerosis (MS). Neurology. 2015;84(14).

6. Boeschoten RE, Braamse AMJ, Beekman ATF, Cuijpers P, Van-Oppen P, Dekker J, et al. Prevalence of depression and anxiety in multiple sclerosis: a systematic review and meta-analysis. J Neurol Sci. 2017;372:331-41. https:// doi.org/10.1016/j.jns.2016.11.067.

7. Hanna M, Strober L. Anxiety and depression in multiple sclerosis (MS): antecedents, consequences, and differential impact on well-being and quality of life. Mult Scler Relat Disord. 2020;44:102261. https://doi.org/10.101 6/j.msard.2020.102261.

8. Butler E, Matcham F, Chalder T. A systematic review of anxiety amongst people with multiple sclerosis. Mult Scler Relat Disord. 2016;10:145-68. https://doi.org/10.1016/j.msard.2016.10.003.

9. Casey B, Uszynski M, Hayes S, Motl R, Gallagher S, Coote S. Do multiple sclerosis symptoms moderate the relationship between self-efficacy and physical activity in people with multiple sclerosis? Rehabil Psychol. 2018; 63(1):104-10. https://doi.org/10.1037/rep0000190.

10. Stromback M, Wiklund M, Salander-Renberg E, Britt-Malmgren-Olsson E. Gender-sensitive and youth friendly physiotherapy: steps toward a stress management intervention for girls and young women. Physiother Theory Pract. 2016;32(1):20-33. https://doi.org/10.3109/09593985.2015.1 075639.

11. Walker A, Kantaris X, Chambers M. Understanding therapeutic approaches to anxiety in vestibular rehabilitation: a qualitative study of specialist physiotherapists in the UK. Disabil Rehabil. 2018;40(7):829-35. https://doi. org/10.1080/09638288.2016.1277393.

12. Walker J, Shepherd W. Anxiety disorders: a nation-wide survey of treatment approaches used by physiotherapists. Physiotherapy. 2001;87(10):536-48. https://doi.org/10.1016/S0031-9406(05)65452-1.

13. Danielsson L, Hansson-Scherman M, Rosberg S. To sense and make sense of anxiety: physiotherapists perceptions of their treatment for patients with generalised anxiety. Physiother Theory Pract. 2013;29(8):604-15. https://doi. org/10.3109/09593985.2013.778382.

14. Olund H, Danielsson L, Rosberg S. Anxiety management: participants experiences of a physiotherapeutic group treatment in Swedish psychiatric outpatient care. Physiother Theory Pract. 2018;18(2):1-15. https://doi.org/1 0.1080/09593985.2018.1485192.

15. Eeltink C, Duffy M. Restorying the illness experience in multiple sclerosis. Family J. 2004;12(3):282-6. https://doi.org/10.1177/10664807042 64567.

16. Flensner $G$, Rudolfsson $G$. Learning to fly with broken wings - forcing a reappraisal of time and space. Scand J Caring Sci. 2015;30(2):403-10. https:// doi.org/10.1111/scs.12262.

17. Michalski D, Liebig S, Thomae E, Singer S, Hinz A, Bergh FT. Anxiety, depression and impaired health-related quality of life are therapeutic challenges in patients with multiple sclerosis. Ment IIIn. 2010;2(1):20-4. https://doi.org/10.4081/mi.2010.e5.

18. Connaughton J, Gibson W. Do physiotherapists have the skill to engage in the "psychological" in the bio-psychosocial approach? Physiother Can. 2016; 68(4):377-82. https://doi.org/10.3138/ptc.2015-66.

19. Markwick R, Singleton C, Conduit J. The perceptions of people with multiple sclerosis about the NHS provision of physiotherapy services. Disabil Rehabil. 2014;36(2):131-5. https://doi.org/10.3109/09638288.2013.782357.

20. Callegaro M, Lozar-Manfreda K, Vehovar V. Web survey methodology. London: SAGE Publications Ltd; 2015.

21. Kara H. Research and evaluation for busy students and practitioners, a time saving guide. 2nd ed. Bristol: Policy Press, University of Bristol; 2017. https:// doi.org/10.2307/j.ctt1t89fsw.

22. Blaikie N. Analyzing quantitative data. London: SAGE Publications Ltd; 2003. https://doi.org/10.4135/9781849208604.

23. Creswell J, Plano Clark VL. Designing and conducting mixed methods research. 3rd ed. California: SAGE Publications Inc; 2018.

24. Patton MQ. How to use qualitative methods in evaluation. 2 rd ed. London: Sage Publications Ltd; 1987. 
25. Braun V, Clarke V. Successful qualitative research, a practical guide for beginners. London: SAGE Publications Ltd; 2013.

26. Silverman D. Doing qualitative research. 5th ed. London: SAGE Publications Ltd; 2017.

27. Saunders B, Sim J, Kingstone T, Baker S, Waterfield J, Bartlam B, et al. Saturation in qualitative research: exploring its conceptualization and operationalization. Qual Quant. 2017;52(4):1893-907. https://doi.org/10.1007/ s11135-017-0574-8.

28. Flick U. An introduction to qualitative research. 4th ed. London: SAGE Publications Ltd; 2009.

29. Braun V, Clarke V. Using thematic analysis in psychology. Qual Res Psychol. 2006;3(2):77-101. https://doi.org/10.1191/1478088706qp063oa.

30. Fereday J, Muir-Cochrane E. Demonstrating rigor using thematic analysis: a hybrid approach of inductive and deductive coding and theme development. Int J Qual Methods. 2006;5(1):80-92. https://doi.org/10.1177/1 60940690600500107

31. Tong A, Flemming K, Mclnnes E, Oliver S, Craig J. Enhancing transparency in reporting the synthesis of qualitative research: ENTREQ. BMC Med Res Methodol. 2012;12(1):1.

32. Cote L, Turgeon J. Appraising qualitative research articles in medicine and medical education. Med Teach. 2005;27(1):71-5. https://doi.org/10.1080/ 01421590400016308.

33. Svenaeus F. Illness as unhomelike being-in-the-world: Heidegger and the phenomenology of medicine. Med Health Care Philos. 2011;14(3):333-42. https://doi.org/10.1007/s11019-010-9301-0.

34. Jingrot M, Rosberg S. Gradual loss of homelikeness in exhaustion disorder. Qual Health Res. 2008;18(11):1511-23. https://doi.org/10.1177/104973230832 5536.

35. Miciak M, Mayan M, Brown C, Joyce AS, Gross DP. The necessary conditions of engagement for the therapeutic relationship in physiotherapy: an interpretive description study. Arch Physiotherapy. 2018;8(3). https://doi. org/10.1186/s40945-018-0044-1.

36. Zangoni G, Thomson OP. 'I need to do another course' - Italian physiotherapists' knowledge and beliefs when assessing psychosocial factors in patients presenting with chronic low back pain. Musculoskelet Sci Pract. 2017;27:71-7. https://doi.org/10.1016/j.msksp.2016.12.015.

37. Singla M, Jones M, Edwards I, Kumar S. Physiotherapists assessment of patients' psychosocial status: are we standing on thin ice? A qualitative descriptive study. Man Ther. 2015;20(2):328-34. https://doi.org/10.1016/j.ma th.2014.10.004

38. csp.org.uk. Chronic pain [online]. England: The Chartered Society of Physiotherapy; 2018. Avaliable from: https://www.csp.org.uk/publications/ physiotherapy-works-chronic-pain

39. britishpainsociety.org. Guidelines for Pain Management Programmes for adults. An evidence based review prepared on behalf of the British Pain Society [online]. London: The British Pain Society; 2013. Available from: https://www.britishpainsociety.org/static/uploads/resources/files/pmp2013_ main_FINAL_v6.pdf

40. Sign.ac.uk. Management of chronic pain (SIGN Guideline No. 136) [online]. Edinburgh: Scottish Intercollegiate Guideline Network; 2014. Available from: https://www.sign.ac.uk/assets/sign136.pdf

41. Wilson S, Chaloner N, Osborn M, Gauntlett-Gilbert J. Psychologically informed physiotherapy practice for chronic pain: patients experiences of treatment and therapeutic process. Physiotherapy. 2017;103(1):98-105. https://doi.org/10.1016/j.physio.2015.11.005.

42. Critchley DJ, McCracken LM, Talewar R, Walker N, Sanders D, Godfrey E. Physiotherapy informed by acceptance and commitment therapy for persistent low back pain: the pact study. Physiotherapy. 2015;101. DOI. 2015. https://doi.org/10.1016/.physio.2015.03.466.

43. Critchley DJ, Galea Holmes M, Wileman V, McCracken L, Godfrey E. "A light bulb moment!" physiotherapists' experience of delivering physiotherapy informed by acceptance and commitment therapy (PACT). Physiotherapy. 2016;102. DOI. 2016. https://doi.org/10.1016/.jphysio.2016.10.285.

44. Neilson M, Keefe FJ, Bennell K, Jull GA. Physical therapist-delivered cognitive behavioural therapy: a qualitative study of physical therapists perceptions and experiences. Phys Ther. 2014;94(2):197-209. https://doi.org/10.2522/ptj.2 0130047.

45. Arvinen-Barrow M, Hemmings B, Weigand D, Becker C, Booth L. Views of chartered physiotherapists on the psychological content of their practice: a follow up survey in the UK. J Sport Rehabil. 2007:16(2):111-21. https://doi. org/10.1123/jsr.16.2.111.
46. Ussing K, Kajaer P, O'Sullivan P. Cognitive functional therapy for the management of a 36Y/O female with a persistent back pain and modic changes type 1. Man Ther. 2016;25:e57-e169. https://doi.org/10.1016/j.ma th.2016.05.125.

47. Schutze R, Rees C, Smith A, Slater H, Campbell JM, O'Sullivan P. How can we best reduce pain catastrophizing in adults with chronic noncancer pain? A systematic review and meta-analysis. J Pain 2018;19(3):233-256. DOl: https:// doi.org/10.1016/j.jpain.2017.09.010.

48. Berman AH, Biguet G, Stathakarou N, Westin-Hagglof B, Jeding K, McGrath $C$, et al. Virtual patients in a behavioural medicine massive open online course (MOOC): a qualitative and quantitative analysis of participants perspectives. Acad Psychiatry. 2017;41(5):631-41. https://doi.org/10.1007/s4 0596-017-0706-4.

49. Wilkening GL, Gannon JM, Ross C, Brennan JL, Fabian TJ, Marcsisin MJ, et al. Evaluation of branched-narrative virtual patients for interprofessional education of psychiatry residents. Acad Psychiatry. 2017;41(1):71-5. https:// doi.org/10.1007/s40596-016-0531-1.

50. Fischer M, Mitsche M, Endler P, Mesenholl-Strehler E, Lothaller H, Roth R. Burnout in physiotherapists: use of clinical supervision and desire for emotional closeness or distance to clients. Int J Ther Rehabil. 2013;20(11): 550-8. https://doi.org/10.12968/ijtr.2013.20.11.550.

51. De Vaus D. Surveys in social research. 6th ed. Oxford: Routledge, Taylor and Francis Group; 2014. https://doi.org/10.4324/9780203519196.

52. Fowler FJ. Survey research methods. 5th ed. California: SAGE Publications Inc; 2014.

\section{Publisher's Note}

Springer Nature remains neutral with regard to jurisdictional claims in published maps and institutional affiliations.
Ready to submit your research? Choose BMC and benefit from:

- fast, convenient online submission

- thorough peer review by experienced researchers in your field

- rapid publication on acceptance

- support for research data, including large and complex data types

- gold Open Access which fosters wider collaboration and increased citations

- maximum visibility for your research: over $100 \mathrm{M}$ website views per year

At BMC, research is always in progress.

Learn more biomedcentral.com/submissions 